\title{
Türk Bankacılık Sektöründe Sermaye Yapısı
}

\author{
Capital Structure in Turkish Banking Sector
}

Hasan Aydın OKUYAN ${ }^{1}$

\section{ÖZET}

Bu çalışmanın amacı, Türk bankalarının sermaye yeterlilik oranlarını etkileyen faktörleri ortaya koyabilmektir.Bu amaçla 23 bankanın 2002:Q04 - 2012Q1 tarihleri arasındaki mali tablolarından elde edilenüçer aylık veriler panel yöntemlerle incelenmiştir. Sonuçta sermaye yeterlilik oranı ile risk, büyüklük, mevduat oranı ve kredi oranı arasında negatif, ekonomik büyüme ve aktif getirisi arasında pozitif bir ilişki olduğu ortaya konulmuştur. Bağımsız değişkenlerden sadece özkaynak karlılığının anlamsız olduğu görülmüştür.

Anahtar Kelimeler: Sermaye yeterlilik oranı, Türk bankacılık sektörü, panel veri

\section{GíRiş}

Modigliani ve Miller'in (1958) sermaye yapısına ilişkin görüşlerinden bu yana şirketlerin sermaye yapılarını açıklamak amacıyla pek çok çalışma yürütülmüş ve çok sayıda kuram ortaya sürülmüştür. Bu kuramlarda genellikle üretim işletmeleri konu edilmiş, bankalar ve diğer mali sektör kuruluşları bu kuramların dışında tutulmuştur. Bundaki temel neden finansal ve finansal olmayan şirketlerin sermayelerini farklı amaçlarla bulunduruyor olmalarıdır. Bu amaç farklılığı, sermaye yapısının da finansal ve finansal olmayan şirketlerde farklı şekilde oluşmasını gerektirmektedir. Üretim işletmeleri için, sermayelerini varlık satın almak, üretim faaliyetlerini sürdürmek veya yeni alanlara yatırım yapmak üzere bulundurulduğu genellemesi yapılabilir. Sermaye, bankalar ve diğer mali sektör şirketleri için de aynı amaçlarla kullanılabilirse de, esas olarak likidite ve kredi yaratmakta kullanmaktadır. Bu açıdanbankalar ve diğer mali sektör kuruluşlarında sermaye yapısının belirleme süreci üretim işletmelerine göre daha farklı gerçekleşebilir.

Bankaların sermaye yapılarının belirlenmesindeki en önemli kısıt yasal zorunluluklardır. Bu konudaki en önemli sınırlamalar, bankaların sermaye yeterliliklerinin ölçülmesine ve değerlendirilmesine ilişkin olarak Basel Bankacılık Denetim Komitesi (Basel Committee

\section{ABSTRACT}

This study analyzes the determinants of capital adequacyratio in the Turkish banking sector. We used a paneldata set that employs bank-level data from the Turkish banking sector covering the quarterly period 2002: Q4 - 2012: Q1. The findings of this study suggest that risk, size, deposit sandloansa renegatively; economic grow thand return on assetsa repositively correlated with capital adequacyratio.

Keywords: Capital adequacyratio, Turkish banking sector, panel data

on Banking Supervision - BCBS) tarafından yayımlanan standartlar bütünüdür. Bu komite 1974 yılında, uluslararası döviz ve bankacılık piyasalarında oluşan önemli krizleri takiben, bankaların risk sınırlarını çizebilmek amacıyla kurulmuştur. Basel Komitesi'nin ülke bankacılık sistemleri ve banka denetim otoritelerini en çok etkileyen düzenlemeleri sermaye yeterliliğine yönelik getirdiği kısıtlamalardır. Bu kapsamda, Basel Komitesi'nin bankacılık sektörünü ortak standartlar içerisinde birleştirmeyi hedeflediği Basel I standartları 1988 yılında yayınlanmış, Basel l'e yönlendirilen eleştirileri gidermek için hazırlanan Basel II düzenlemeleri ise 2004 yılında yayınlanmıştır. Bu düzenlemelere ek olarak 2010 yılında Basel III standartları da yayınlamıştır. Bu standartlar sermaye yeterliliği hesaplama felsefesinde önemli sapmalar meydana getirmemektedir. Başka bir deyişle; Basel III, Basel II gibi sermaye gereksinimi hesaplanma usulünü tümden değiştiren bir "devrim" değildir. Ancak Basel II'nin özellikle son finansal krizdeki gözlemlenen eksikliklerini tamamlayan bir "ek düzenlemeler seti" niteliğindedir. Basel l'de "Toplam Sermaye / Kredi Riski + Piyasa Riski>\%8" olarak tanımlanan minimum sermaye oranı, Basel II'de "Toplam Sermaye / Kredi Riski + Piyasa Riski + Operasyonel Risk>\%8" olarak düzeltilmiştir. 
Basel III'de ise bu hesaplama yöntemi değişmemiş ancak yeni kurallar setinde, mevcut özkaynak ve sermaye yeterliliği hesaplamasında önem arz eden sermayenin niteliğinin ve niceliğinin artırılmasına ilişkin standartlar ile dönemselliğe bağlı olarak kullanılacak ilave sermaye tamponu oluşturulması gibi başlıklar mevcuttur. Bahsi geçen hususlara ilave olarak daha önce Basel II uygulamalarının en büyük eksikliği olarak görülen likidite yeterlilik ve risk bazlı olmayan kaldıraç oranları gibi hususlarda da yeni düzenlemeler getirilmiştir (BDDK, 2010:1).

BDDK verilerine göre Türkiye'deMart 2012 tarihi itibariyle bankaların ortalama sermaye yeterliliği oranı \%16,6 olup, bu oran uluslararası otoriteler tarafından önerilen ve Türk Bankacılık Kanunu ile belirlenen \%8'in oldukça üzerindedir. Bu oran bankaların yasal sınırların altında bir borç oranı ile çalıştıklarını göstermektedir. Bu durum bankaların sermaye yapılarının belirlenmesinde yasal sınırların dışında faktörlerin bulunduğuna işaret etmektedir. Bu çalışmada bu faktörlerin neler olduğu ortaya konulmaya çalışılacaktır.

Bu çalışmanın amacı bankaların sermaye yapılarını, diğer bir ifade ile sermaye yeterlilik oranını belirleyen değişkenlerin açıklanmasıdır. Çalışmanın birinci bölümünde konuya giriş yapılmıştır. İkinci bölümde konu ile ilgili literatür incelenmiştir. Üçüncü bölümde veri seti, yöntem ve sermaye yeterlilik oranı üzerinde etkili olan değişkenler açıklanmıştır.Dördüncü bölümde model seçimi anlatılmış ve bulgular tartışılmıştır. Çalışma beşinci bölüm olan sonuç bölümü ile tamamlanmıştır.

\section{LITERATÜR}

Literatürde yer alan çalışmalarda banka büyüklüğü, varlık getirisi, kredi karşılıkları, mevduat ve riskli varlıklar gibi kalemlerin sermaye yeterlilik oranı üzerinde etkili olup olmadığı araştırılmıştır.

Koehn ve Santomero (1980) çalışmalarında sermaye yeterliliği düzenlemelerinin ticari bankaların varlık portföyleri üzerindeki etkisini araştırmıştır. Çalışmada bankalara yönelik yasal düzenlemelerin temel hedefinin, bankanın riskini azaltmak ve istikrar ve canlılığı artırmak olduğu varsayımından hareket etmişlerdir. Sonuçta karlılıktaki veya sermaye oranındaki artışın başarısızlık ihtimalini azalttığı sonucuna varmışlardır. Madura ve Zarruk (1993) bu görüşü destekleyen sonuçlara ulaşmışlardır. Banka hisselerinde yaptıkları araştırmada, bankacılık sektörüne yönelik yeni sermaye oranı düzenlemelerinin, yatırımcılar tarafından riski düşüren ve bankayı optimal bir sermaye yapısına doğru yönlendiren düzenlemeler olarak algılandığını söylemişlerdir. Mpuqa (2002) banka- larda minimum sermaye oranına yönelik düzenlemelerin olmamasının banka başarısızlıklarındaki en önemli faktörlerden biri olduğunu öne sürmüştür. Choi (2002) bankalar yönelik sermaye düzenlemelerinin Güney Kore bankacılık sektöründe riskin azaltılması yönünde etkili olduğunu ifade etmiştir. Buna göre düzenlemelerden önce \%59 olan sermaye eksikliği oranının 1997 yılındaki düzenlemelerden sonra \%26'ya düştüğünü söylemiştir. Lin (2002) düşük sermayeli bankaların düşük verim ve karlılıkla çalıştıklarını öne sürmüştür. Bu görüşü destekler şekilde Mathuva (2009) bankaların karlılığı ile sermaye oranları ve risk bazlı sermaye oranları arasında pozitif bir ilişki bulunduğunu öne sürmüştür. Sermaye ve risk bazlı sermaye oranları artan bankaların daha karlı çalıştıklarını ifade etmiştir.

Yukarıda ifade edilen görüşlerin tersine Kahane (1977), Koehn ve Santomero (1988), Hovakimian ve Kane (2000), sermaye yeterliliği düzenlemelerinin bankaların risklerini artırmalarını engellemediğini öne sürmüşlerdir. Sıkı sermaye yeterliliği standartlarının riski denetleme ve kontrol faaliyetlerinin yerine geçmeyeceğini öne sürmüşlerdir. Sıkı sermaye yeterliliği düzenlemelerinin olması halinde banka yöneticilerinin ellerinde daha riskli varlıklar bulundurmayı uygun bulacaklarını ifade etmişlerdir. Gennotte ve Pyle (1991), Rochet (1992) bu görüşü destekler şekilde, kaldıracın azaltılması diğer bir ifade ile sermayenin artırılması için sıkıştırılan bankaların ellerindeki varlıkların risklerini artırarak farkı ikame edeceklerini öne sürmüşlerdir.

Blose (2001) 1980-1993 yılları arasında kredi karşılıklarında artış olduğuna ilişkin duyuruların etkilerini incelenmiştir. 213 duyuru döneminde yapılan incelemede yatırımcıların duyurulara olumsuz tepki verdikleri ve bu durumun hisse senedi fiyatlarını düşürdüğünü öne sürmüştür. Ayrıca sermaye yeterliliği konusunda problem yaşayan bankalara ait hisse senetlerinde diğerlerine oranla belirgin şekilde fiyat düşüşleri yaşandığını tespit etmiştir. Tanaka (2002) bankalara yönelik sermaye yeterliliği düzenlemelerinin parasal aktarım mekanizmaları üzerindeki etkilerini ortaya koymaya çalıştığı çalışmasında, sermaye yeterliliği düzenlemelerinin çok sıkı olduğu veya bankaların sermayelerinin yeterli olmadığı durumların parasal aktarım mekanizmasını zayıflattığı sonucuna varmıştır. Hassan (1992) bankaların bilanço dışı faaliyetlerinin ve ek kredi mektuplarının (standbycreditletters-SLC) piyasa düzenleyici kurumlar için endişe verici olduğunu, yapılan yasal düzenlemelerin genellikle bunları ortadan kaldırmaya yönelik olduğunu ifade etmiştir. Ayrıca gelişmekte olan 
ülkelerin çoğunda sermaye yeterliliği seviyesinin temel belirleyicisinin makroekonomik veriler olduğunu öne sürmüştür. Ajayi (2008) sermaye yeterliliği oranı, karlılık ve risk primi üzerinde makro enflasyon ve büyüme gibi makro ekonomik değişkenlerin etkili olduğu tespit etmiştir. Ho ve Hsu (2010) bankaların sermaye yapısının ülkenin ekonomik konjonktüründen etkilendiğini öne sürmüşlerdir.

Asarkaya ve Özcan (2007) Türk bankacılık sektöründe sermaye yapısının belirleyicileri analizettikleri çalışmalarında bankaların düzenlemelerdekinden daha fazla sermaye tutmasını açıklayacakdeğişkenleri belirlemeye çalışmışlardır. Sonuçta portföyriskinin, ekonomik büyümenin, sektörün ortalama sermayesinin ve sermaye getirisini tutulan sermaye ile pozitif ilişkili olduğunu; buna karşılık varlık büyüklüğününve mevduat payının negatif ilişkili olduğunu söylemişlerdir. Büyükşalvarcı ve Abdioğlu (2011) çalışmalarında sermaye yeterlilik oranının belirleyicilerini ortaya koymaya çalışmışlardır. Sonuçta sermaye yeterlilik oranı üzerinde varlık getirisi ve kaldıracınnegatif, kredi zararı karşılıkları ve özkaynak getirisinin pozitif etkisi olduğunu öne sürmüşlerdir.

\section{VERI SETI VE DEĞişKENLER}

Mart 2012 tarihi itibariyle Türkiye'de iş gören 31 mevduat bankası bulunmaktadır. Bunlardan 3 tanesi kamusal, 12 tanesi özel sermayeli ve 16 tanesi yabancl sermayelidir. Özel sermayeli bankalardan fon tarafından işletilen ve verilerinde eksiklik bulunan 1'er banka ve yabancı sermayeli bankalardan Türkiye'de şube açan 6 banka çıkarılarak kalan 23 banka çalışmanın veri setini oluşturmaktadır.

31.12.2011 tarihi itibariyle veri setini oluşturan bankalar toplam aktiflerin \%95,6'sını, toplam kredilerin \%95,6.'sını ve toplam mevduatın \%99,6'sını elinde bulundurmaktadır. Yani çalışmada kullanılan veri setinin temsil gücü oldukça yüksektir. Çalışmada 2002:Q04 - 2012Q1 tarihleri arasındaki üçer aylıkveriler incelenmiştir. 23 bankaya ait 38 dönemlik 874 gözlemlik panel yöntemlerle incelenecektir.

Çalışmada kullanılan model aşağıda gösterilmiştir:

$$
\begin{aligned}
& S Y_{i t}=\alpha+\beta_{1} R S_{i t}+\beta_{2} A K_{i t}+\beta_{3} R O E_{i t} \\
& +\beta_{4} R O A_{i t}+\beta_{5} M V_{i t}+\beta_{6} G_{i t}+\beta_{6} K R_{i t}+\varepsilon_{i t} \\
& \mathrm{i}=1, \ldots \ldots ., \mathrm{N} \quad \mathrm{t}=1, \ldots \ldots . \mathrm{T}
\end{aligned}
$$

Modelde yer alan SYsermaye yeterlilik oranını ifade etmektedir ve toplam sermayenin risk ağırlıklı unsurlara oranı seklinde hesaplanmaktadır. Modelde $\mathrm{i}$ işletmeyi, $\mathrm{t}$ ise dönemleri temsil etmektedir. $\mathrm{N}$ top- lam işletme sayısını gösterirken, T toplam dönem sayısını göstermektedir.

Çalışmada, belirlenen amaca uygun olarak seçilen değişkenlerin sermaye yeterlilik oranı üzerindeki etkisi ortaya konulmaya çalışılacaktır. Daha önce açıklandığı üzere bankalar sermaye yapılarına karar verirken, sermaye yeterlilik oranlarını sınırlayan yasal düzenlemelerin yanında bir takım içsel değişkenlere de bakarlar. Bu çalışmada bu değişkenlerin neler olduğu geçmiş çalışmalar ışığında ortaya konulmaya çalışılacaktır.

Modeldeki bağımsız değişkenlerden ilki olan risk (RS), bankanın üstlendiği riski ifade etmektedir ve risk ağırlıklı unsurların toplam varlıklara oranı şeklinde hesaplanmaktadır. Bankadaki risk artışının sermaye yeterliliği üzerindeki etkisi bu değişkenin katsayısı ile ortaya konulmaya çalışılacaktır. Asarkaya ve Özcan (2007) risk ile sermaye yeterlilik oranı arasında negatif bir ilişki beklenmesi gerektiğini ifade etmişlerdir. Alfon ve diğerleri (2004) mevduat sigortası sisteminin varlığının bankaların risk almasını kolaylaştırdığını söylemişlerdir.

Bankanın aktif büyüklüğünün (AK) sermaye yeterlilik oranı üzerinde etkili olması beklenebilir. Jackson ve diğerleri (2002) büyük bankaların şöhretlerini koruyabilmek için fazla sermaye yeterliliklerini yüksek tutma eğiliminde olduklarını söylemiştir. Bu görüşe ters şekilde Kleff ve Weber (2003), Wong ve diğerleri (2005) ve Gropp ve Heider (2007), büyük bankaların risk yönetim teknikleri konusunda küçüklere oranla daha etkin bir çalışma yürütebildikleri ve sermaye ihtiyaçlarını küçüklere oranla dışarıdan görece kolay sağlayabildikleri için aktif büyüklük arttıkça sermaye yeterlilik oranının düştüğünü ifade etmişlerdir. Çalışmada büyüklüğü temsilen Asarkaya ve Özcan (2007)'nın yaptığı gibi enflasyondan arındırılmış aktif büyüklüğünün doğal logaritması kullanılmıştır.

Karlılığın, sermaye yeterlilik oranı üzerindeki etkisini ortaya koyabilmek için çalışmaya özkaynak getirisi (ROE) değişkeni eklenmiştir. Asarkaya ve Özcan (2007) sermaye maliyeti düşük olduğunda, sermaye yeterlilik oranının artmasının karlılığı etkilemeyeceğini öne sürmüşlerdir. Çalışmalarında sermayenin alternatif maliyetini temsilen özkaynak getirisini kullanmışlardır. Gropp ve Heider (2007), Asarkaya ve Özcan (2007), Büyükşalvarcı ve Abdioğlu (2011) özkaynak getirisi ile sermaye yeterlilik oranı arasında pozitif bir ilişki olduğunu öne sürmüşlerdir. Modele karlıı̆ın bir başka göstergesi olan aktif getirisi (ROA) de eklenmiştir. 
Kleff ve Weber (2003) mevduatların diğer kaynaklara oranla daha ucuz bir kaynak yarattığını öne sürmüşlerdir. Asarkaya ve Özcan (2007) mevduatlardaki azalışın toplam kaynak maliyetini artıracağını, bu artışı karşılayabilmek için bankanın daha çok sermayeye ihtiyaç duyacağını öne sürmüşlerdir. Çalışmada mevduatların sermaye yeterlilik oranı üzerindeki etkisi mevduatların toplam yükümlülükler içindeki payı şeklinde hesaplanan değişken (MV) yardımıyla hesaplanacaktır.

Ekonomik büyüme (G) de bağımsız değişken olarak modele dahil edilmiştir. Ekonominin küçüldüğü dönemlerde bankalar daha sağlam bir yapı sergileyebilmek ve küçülmenin getirdiği problemleri daha az yaşamak için ellerinde daha yüksek oranlarda sermaye tutma eğilimindedirler. Ekonomik büyüme dönemlerinde ise dışarıdan istenen anda sermaye bulma imkanları daha fazla olacağından daha az sermaye tutma imkanları bulunabilir. Çalışmada ekonomik büyümenin göstergesi olarak gayrısafi yurtiçi hasıla artış oranı kullanılmıştır.
Mpuga (2002) sermaye yeterlilik oranı ile kredilerin arasında pozitif bir ilişki olduğunu öne sürmüştür. Bu görüşün tersine Büyükşalvarcı ve Abdioğlu (2011) ise sermaye yeterlilik oranı ile krediler arasında negatif bir ilişkiye rastlamışlardır. Modelde krediler (KR), kredilerin varlıklara oranı şeklinde hesaplanarak kullanılmıştır.

Tablo 1'de çalışmanın veri setini oluşturan 874 gözleme ait tanımlayıc istatistiklere yer verilmiştir. Tablo $2 a$ ve $2 b$ değişkenler arasındaki çoklu bağlantı sorunu olup olmadığını ortaya koymak üzere yapılmış testleri göstermektedir. Çoklu bağlantı değişkenlerin tümünün veya bazılarının kendi aralarında güçlü bir ilişki içinde olmalarını ifade etmektedir. Tablo 2a, değişkenler arasındaki korelasyonu göstermektedir. Tablo $2 \mathrm{~b}$ ise "varyans büyütme faktörü" (VIF) ve Tolerans katsayılarını göstermektedir.VIF için kritik değer literatürde genelde 5 olarak kabul edilmektedir ve bulunan değer 5 'ten büyükse çoklu bağlantı sorunun var olduğuna karar verilmektedir (Tarı, 2008). Benzer şekilde tolerans katsayısı için ise kritik değer $0.2^{\prime}$ dir ve elde edilen değer bu değerden küçük ise çoklu bağlantı sorunun var olduğuna karar verilmektedir (Wooldridge, 2000).

Tablo 1: Değişkenlere Ait Tanımlayıcı İstatistik Tablosu

\begin{tabular}{|c|c|c|c|c|}
\hline $\begin{array}{c}\text { Değişkenler } \\
\mathrm{N}=874\end{array}$ & Ortalama & $\begin{array}{c}\text { Standart } \\
\text { Sapma }\end{array}$ & Minimum & Maksimum \\
\hline SY & 0.187 & 0.862 & 0.119 & 0.684 \\
\hline RS & 0.623 & 0.157 & 0.275 & 0.852 \\
\hline AK & 21.654 & 1.534 & 18.573 & 26.85 \\
\hline ROE & 0.134 & 0.0823 & -0.213 & 0.334 \\
\hline ROA & 0.021 & 0.011 & -0.027 & 0.49 \\
\hline MV & 0.683 & 0.128 & 0.116 & 0.862 \\
\hline G & 0.016 & 0.005 & -0.052 & 0.095 \\
\hline KR & 0.54 & 0.18 & 0.045 & 0.786 \\
\hline
\end{tabular}

Tablo 2a: Değişkenlere Ait Çapraz Korelasyon Tablosu

\begin{tabular}{|c|c|c|c|c|c|c|c|}
\hline & SY & RS & AK & ROE & ROA & MV & G \\
\hline SY & 1 & & & & & & \\
\hline RS & $-0,163$ & 1 & & & & & \\
\hline AK & $-0,647$ & $-0,156$ & 1 & & & & \\
\hline ROE & $-0,354$ & 0,743 & 0,563 & 1 & & & \\
\hline ROA & 0,612 & 0,256 & 0,234 & 0,765 & 1 & & \\
\hline MV & $-0,541$ & $-0,522$ & 0,423 & $-0,532$ & $-0,489$ & 1 & \\
\hline G & 0,025 & 0,657 & 0,002 & 0,128 & 0,012 & $-0,213$ & 1 \\
\hline KR & $-0,420$ & 0,457 & 0,732 & $-0,326$ & $-0,257$ & 0,561 & 0,321 \\
\hline
\end{tabular}

Tablo 2b'deki verilere göre açıklayıcı değişkenler arasında çoklu bağlantı sorunu bulunmamaktadır.

\section{MODEL SEÇIMI VE TAHMIN SONUÇLARI}

Panel veri kullanılarak yapılan uygulamalı çalışmalarda genel olarak iki model kullanılmaktadır. Bunlar sırasıyla "sabit etki (fixed effects)" ve "rassal etki (random effects)" modelleridir. Burada boş hipotez altında etkin tahmin edici "ortak regresyon" (pooled OLS)
Tablo 2b: Açıklayıcı Değişkenler Arasında Çoklu Bağlantı Testi

\begin{tabular}{|c|c|c|}
\hline & VIF & $\begin{array}{c}\text { Tolerans } \\
\text { Katsayıları }\end{array}$ \\
\hline SY & 1.5 & 0.348 \\
\hline RS & 1.16 & 0.874 \\
\hline AK & 1.74 & 0.942 \\
\hline ROE & 1.90 & 0.812 \\
\hline ROA & 1.42 & 0.529 \\
\hline MV & 1.98 & 0.429 \\
\hline G & 1.27 & 0.534 \\
\hline KR & 1.76 & 0.268 \\
\hline
\end{tabular}

iken, alternatif hipotez altında etkin tahminci "sabit etki" (fixed effect) modelidir. Çalışmanın bulgularının sunulduğu Tablo 3'ün 1. kolonda yer alan F-testi sonucuna göre elde edilen test istatistiği değeri (7.598) yüzde 1 anlamlılık düzeyinde istatistiki olarak anlamlı bulunmuştur. Dolayısıyla, boş hipotez reddedilmiştir ve ilgili iki model arasında sabit etki modeli tercih edilmiştir. 
Panel veri ile yapılan çalışmalarda sabit etki modeli kullanılabileceği gibi "rassal etki modeli" de kullanılabilir. Rassal etki modelinde tesadüfi etkinin sıfır olup olmadığı Breusch - Pagan (1980) testi ile test edilmektedir. Boş hipotezin reddedilmesi tesadüfi etki modelinin ortak (pooled) regresyon modeline karşı tercih edilmesi gerektiğine işaret etmektedir.
Çalışmanın bulgularının sunulduğu Tablo 3'ün 2. kolonunda yer alan Breusch-Pagan testi sonucuna göre elde edilen test istatistiği değeri $(9271,59)$ yüzde 1 anlamlılık düzeyinde istatistiki olarak anlamlı bulunmuştur. Dolayısıyla, "sıfır" rassal etki boş hipotezi reddedilir.

Tablo 3:Sermaye Yeterlilik Oranının Belirleyicileri

\begin{tabular}{|c|c|c|c|}
\hline & $\begin{array}{c}\text { Bağımlı } \\
\text { Değişken: } \\
\text { Ser. Yet. Or (SY) } \\
\text { Sabit Etki Modeli }\end{array}$ & $\begin{array}{c}\text { Bağımlı } \\
\text { Değişken: } \\
\text { Ser. Yet. Or } \\
\text { (SY)Rassal Etki } \\
\text { Modeli }\end{array}$ & $\begin{array}{l}\text { Bağımlı } \\
\text { Değişken: } \\
\text { Ser. Yet. Or } \\
\text { (SY)FGLS } \\
\text { Modeli }\end{array}$ \\
\hline Risk (RS) & $\begin{array}{c}-0.195^{* * *} \\
{[0.021]}\end{array}$ & $\begin{array}{c}-0.206^{* * *} \\
{[0.019]}\end{array}$ & $\begin{array}{c}-0.254^{* * *} \\
{[0.029]}\end{array}$ \\
\hline Büyüklük (AK) & $\begin{array}{c}-8.137^{* * *} \\
{[1.853]} \\
\end{array}$ & $\begin{array}{c}-7.019 * * * \\
{[1.459]}\end{array}$ & $\begin{array}{c}-9.594^{* * *} \\
{[1.972]}\end{array}$ \\
\hline Özkaynak Getirisi (ROE) & $\begin{array}{l}0,00021 \\
{[0.0001]}\end{array}$ & $\begin{array}{l}0,00038 \\
{[0.0002]}\end{array}$ & $\begin{array}{l}0.00074 \\
{[0.0032]}\end{array}$ \\
\hline Aktif Getirisi (ROA) & $\begin{array}{c}1.098^{* * *} \\
{[0.306]}\end{array}$ & $\begin{array}{c}1.135^{* * *} \\
{[0.511]}\end{array}$ & $\begin{array}{c}1.108^{* * *} \\
{[0.509]}\end{array}$ \\
\hline Mevduat Oranı (MV) & $\begin{array}{c}-0,154^{* *} \\
{[0.021]}\end{array}$ & $\begin{array}{c}-0,145^{* * *} \\
{[0.015]}\end{array}$ & $\begin{array}{c}-0.018^{* *} \\
{[0.009]}\end{array}$ \\
\hline Ekonomik Büyüme (G) & $\begin{array}{c}0,259 * * * \\
{[0.103]}\end{array}$ & $\begin{array}{l}0,262^{* *} \\
{[0.098]}\end{array}$ & $\begin{array}{c}0.342^{* * *} \\
{[0.115]}\end{array}$ \\
\hline Kredi Oranı (KR) & $\begin{array}{l}0.764^{* *} \\
{[0.056]}\end{array}$ & $\begin{array}{c}0.429 * * * \\
{[0.038]}\end{array}$ & $\begin{array}{c}0.639 * * * \\
{[0.051]}\end{array}$ \\
\hline F-Test Pool & $7.598^{* * *}$ & & \\
\hline Hausman Testi & & $35,49 * * *$ & \\
\hline Breusch - Pagan & & $9271.59 * * *$ & \\
\hline $\mathrm{R}^{2}$ & 0.639 & 0.592 & 0.672 \\
\hline Wald Ki-Kare & & $13895.70^{* * *}$ & $710.2^{* * *}$ \\
\hline F Değeri & $2839.39 * * *$ & & \\
\hline Gözlem Sayısı & 874 & 874 & 874 \\
\hline Banka Sayısı & 23 & 23 & 23 \\
\hline
\end{tabular}

Her ne kadar Tablo 3'de yer alan tahmin sonuçları aşırı derecede değişkenlik göstermese de, sabit etki ve rassal (ya da tesadüfi) etki modelleri arasında seçim yapabilmek amacıyla, modeller yuvalanmış ("non-nested") formatta ya da modellerden biri diğerinin sınırlı hali olmadığı için, "Hausman" spesifikasyon testi kullanılmaktadır. Bu testte, boş hipotez sabit etki modeli ile rassal etki modelinin parametreleri arasındaki farklılığın sistematik olmadığı şeklinde ifade edilmektedir. Boş hipotezin reddedilmesi, sabit etki modelinin rassal etki modeline tercih edilmesi gerektiğini göstermektedir. (Berke, 2009;41). Bulgulara göre, "Hausman" spesifikasyon test istatistik değeri 35.49'dur, dolayısıyla sabit etki modeli rassal etki modeline tercih edilmiştir.

Bununla birlikte tahminler sonrasında her iki model için de değişen varyans ve otokorelasyon prob- lemleri ile karşılaşılmıştır1. Bu sorunlardan kurtulmak ve daha güvenilir sonuçlar elde edebilmek için literatürde genel olarak iki tür yaklaşım kullanılmaktadır. Bunlardan ilki "Uygun Genelleştirilmiş En Küçük Kareler Yöntemi - Feasible Generalized Least Squares (FGLS)", diğeri ise Prais -Winsten yaklaşımı olarak da bilinen "Standart Hataları Düzeltilmiş Panel-Panel CorrectedStandardErrors (PCSE)" yöntemidir. Beck ve Katz (1995)'ın çalışması, yatay kesit boyutu zaman boyutundan daha büyük olan veri setlerinde PCSE yaklaşımının daha sağlıklı sonuçlar verdiğini göstermiştir. Bu çalışmadaki veri setinin yatay kesit boyutu (23banka) zaman boyutundan (38 dönem) daha büyük olduğundan tahminler FGLS yaklaşımı ile yapılmıştır. FGLS yaklaşımında model birinci derece otokorelasyon (AR1) sorunundan arındırılmıştır (Ayrıntılı bilgi için bkz. Beck ve Katz (1995 ve 1996)). Ayrıca de- 
ğişen varyans sorununu düzeltmek için sağlam (robust) standart hatalar elde edilmiştir ve çalışmanın bundan sonraki kısmında bulgular seçilen bu modele göre değerlendirilecektir.

Elde edilen sonuçlar incelendiğinde sermaye yeterlilik oranı ile risk, büyüklük,mevduat oranı ve kredi oranı arasında negatif, ekonomik büyüme ve aktif getirisi arasında pozitif bir ilişki olduğu görülmektedir. Elde edilen sonuçların literatürde yer alan bazı çalışmalar ile uyumlu olduğu görülmektedir.

Bankanın sermaye yeterlilik oranıyla, portföylerinde bulunan riskli varlıklar arasında negatif bir ilişki tespit edilmiştir. Portföyde bulundurulan riskli varlık oranı arttıkça bankaların sermaye yeterlilik oranlarının azaldığı görülmektedir. Asarkaya ve Özcan (2007) ile Ahmad ve diğerleri (2008)'e göre bu durum yüksek portföy riskine sahip bankaların, üstlendikleri yüksek riske bağlı olarak beklenen veya beklenmeyen kayıpları karşılayabilmek için yüksek oranda sermaye ile çalıştıklarının bir göstergesi olabilir.

Büyüklük ile sermaye yeterlilik oranı arasındaki negatif ilişki büyük bankaların daha düşük sermaye ile çalıştıklarına işaret etmektedir. Jacques ve Nigro (1998) bu durumu büyük bankaların sermayelerini artırma konusunda küçükler kadar baskı altında olmamalarına bağlamaktadır. Asarkaya ve Özcan (2007) ise büyük bankaların daha etkin yönetim teknikleri kullandıklarından daha düşük sermaye yeterlilik oranları ile çalışabildiklerini öne sürmektedirler.

Bankaların mevduat oranı ile sermayeleri arasında negatif bir ilişki olduğu ortaya konulmuştur. Bu durum mevduat oranlarındaki azalışların kaynak maliyetini artıracağını, artan kaynak maliyetini karşılamak için bankaların daha yüksek oranlarda sermayeye ihtiyaç duymaları ile açıklanabilir.

Sermaye yeterlilik oranı ile aktif karlılığı arasında pozitif bir ilişki tespit edilmiştir. Varlık karlılığı birim varlık başına düşen karlılığı göstermektedir. Karlılık oranı arttıkça bu aynı zamanda bankanın sermayesini de artıracaktır. Elde edilen sonuçlar Büyükşalvarcı ve Abdioğlu (2011) ile uyumludur. Özkaynak karlılığı değişkeninin ise anlamsız olduğu görülmüştür.

Bankaların kredi oranları ile sermaye yeterlilik oranları arasında negatif bir ilişski olduğu görülmüştür. Bu durum bankaların sermayelerini kredi vermekten çok başka alanlara yatırımda kullandıklarının bir göstergesi olabilir.

Bankaların sermaye yeterlilik oranlarının ekonomik büyüme dönemlerinde arttığı görülmektedir.
Asarkaya ve Özcan (2007) bu durumu ekonomik büyüme dönemlerinde bankaların karlılıklarında artış ile açıklamaktadır. Büyüme dönemlerinde banka karlılıklarında artışlar meydana geldiğini, bu artan karların da sermayeye eklenmesi ile sermaye yeterlilik oranlarını arttığını öne sürmektedirler.

\section{SONUÇ}

Bu çalışmada Türk bankacılık sektörünün sermaye yapısını etkileyen unsurlar ortaya konulmaya çalışılmıştır. Bankacılık sektörü kritik öneminden dolayı kanuni bazı sınırlamalarla karşı karşıyadır. Bu sınırlamalar Basel kriterlerini baz almaktadır. Bu kriterler bankaların aşırı borçlanmasını engellemeye çalışmak ve sermayelerinin ancak belirli bir katı kadar riskli varlık bulundurmalarına izin vermektedir. Türk bankacılık sektörü verilerine bakıldığında bankaların bu yasal sınırların çok altına çalıştıkları görülmektedir. Dolayısıyla bankalarda sermaye düzeyini belirleyen, yasal sınırlardan başka faktörlerin de olduğu söylenebilir. Bu çalışmada sermaye yeterlilik oranı olarak adlandırılan bu sermaye düzeyinin belirleyicileri ortaya konulmaya çalışılmıştır. Bu amaçla farklı çalışmalarda modellere dahil edilmiş değişkenler kullanılmıştır. Çalışmada bağımsız değişkenler olarak bankanın üstlendiği risk, bankanın aktif büyüklüğü, özkaynak ve aktif karlıığı, mevduat oranı, ekonomik büyüme ve kredi oranı kullanılmıştır. Sonuçta sermaye yeterlilik oranı ile risk, büyüklük, mevduat oranı ve kredi oranı arasında negatif, ekonomik büyüme ve aktif getirisi arasında pozitif bir ilişki olduğu görülmektedir. Özkaynak karlılığı değişkeninin ise anlamsız olduğu görülmüştür.

Bankaların sermaye yapılarını etkin bir şekilde yönetebilmeleri için sermaye yapısı üzerinde etkili olan faktörlerin net olarak ortaya konulmuş olması gerekmektedir. Bu çalışmada bu faktörlerin ortaya konulmasına çalışılmıştır. Bankalar diğer işletmelerden farklı olarak yönetim yapılarına müdahalelerde bulunulan kurumlardır. Bu durum bankaların finansal sistemin ve ulusal ekonominin en temel kurumları olmalarından kaynaklanmaktadır. Bu nedenle bankalar bir taraftan yasal zorunluluk nedeniyle bazı sınırlamalara uymak zorunda iken, diğer yandan taşıdıkları önem ve rekabet koşulları nedeniyle, kaynakların etkin yönetimine daha çok eğilmeye başlamışlardır.

Elde edilen bu sonuçların çoğunluğu literatürile uyumlu olmakla birlikte, literatüre ters bazı sonuçlar da bulunmaktadır. FarklılıklarTürk ekonomisinin kendine has koşullarından kaynaklanmış olabilir. Ayrıca çalışmanın konusunu teşkil eden dönem de sonuçların farklı çıkmasının nedeni olabilir. Çalışmanın alt dönemler itibariyle tekrarlanması sonuçlarda değişikliğe yol açabilir.

1 Literatürde, değişen varyansın tespiti için "Wald" testi, otokorelasyonun (birinci dereceden) tespiti için 


\section{SON NOTLAR}

ise Woolridge (2000) yaklaşımı kullanılmaktadır. Bu çalışmada her iki model için de bu sorunlara rastlanmıştır. Gerek sabit gerekse rassal etki varsayımları altında elde edilen sonuçlar ve yukarıda ifade edilen testlere ilişkin sonuçlar istendiğinde yazardan temin edilebilir.

${ }^{2}$ Bkz. Sorensen ve diğerleri (2001), Chang ve diğgerleri
(2003), Rudra (2005), Ghazalian ve Furtan (2007), York (2007), Bellak ve diğerleri (2008), Kim ve Jennings (2009), Jorgenson (2009).

\section{KAYNAKLAR}

Ahmad R., Ariff M. ve Skully M.J. (2008) "The Determinants of Bank Capital Ratios in a DevelopingEconomy" Asia-Pacific Financial Markets, 15(3-4):255-272.

Alfon I., Argimón I., ve Bascuñana-Ambrós, P. (2005) "How Individual Capital Requirements Affect Capital Ratios in UK Banksand Building Societies" Banco de España Working Paper, No:0515.

Angbazo, L. (1997) "Commercial Bank Net Interest Margins, Default Risk, Interest-Rate Risk and Off-Balance Sheet Banking" Journal of Bankingand Finance, 21:55-87.

Asarkaya Y. ve Özcan S. (2007) "Determinants of Capital Structures in Financial Industries: The Case of Turkey” BDDK Finansal Piyasalar Dergisi, 1:91-109.

Bankacılık Düzenleme ve Denetleme Kurulu (2012) "Finansal Piyasalar Raporu” 25:1-65

Beck, N. ve Katz, J. N. (1995) "What To Do (and Not to Do) With Time-Series Cross-Section Data" American Political Science Review, 89(3):634-647.

Beck, N. ve Katz, J.N. (1996) "Nuisance vs. Substance: Specifying and Estimating Time-Series CrossSection Data” Political Analysis, 6(1):1-36.

Berke, B. (2009) "Avrupa Parasal Birliğinde Kamu Borç Stoku ve Enflasyon İlişkisi: Panel Veri Analizi” Ekonometri ve Ístatistik, 9:30-55.

Bellak, C., Leibrecht, M. ve Reidl, A. (2008) "Labour Costs and FDI Flows into Central and Eastern European Countries: A Survey of the Literature and Empirical Evidence" Structural Changeand Economic Dynamics, 19(1):17-37.

Blose, L.E. (2001) "Information Asymmetry Capital Adequacy, and Market Reaction to Loan Loss Provision Announcements in the Banking Industry" The Quarterly Review of Economicsand Finance, 14(2):239-258.
Büyükşalvarcı, A. ve Abdioğlu, H. (2011) "Determinants of Capital Adequacy Ratio in Turkish Banks: A Panel Data Analysis" African Journal of Business Management, 5(27):11199-11209.

Chang, H., Koski, H. ve Majumdar, S.K. (2003) "Regulation and Investment Behaviour in the Telecommunications Sector: Policies and Patterns in US and Europe" Telecommunications Policy, 27(10-11):677699.

Choi, G.(2000) "The Macroeconomicimplications of Regulatory Capital Adequacy Requirements for Korean Banks” Economic Notes, 29(1):111-143.

Gennotte, G. ve Pyle, D. (1991) "Capital Controls and Bank Risk” Journal of Bankingand Finance, 15:805-824.

Ghazalian, P.L. ve Furtan, W.H. (2007) “The Effect of Innovation on Agriculturaland Agri-food Exports in OECD Countries" Journal of Agriculturaland Resource Economics, 32(3): 448-461.

Gropp, R ve Heider, F. (2007) "What Can Corporate Finance Say About Banks' Capital Structures?” European Central Bank Working Paper.

Hassan K. (1992) "An Empirical Analysis of Bank Standby Letters of Credit Risk" Review of Financial Economics, 2(1):31-44.

Ho S.J. ve Hsu S.C. (2010) "Leverage, Performance and Capital Adequacy Ratio in Taiwan's Banking Industry" Japan andthe World Economy,22:264-272.

Hovakimian, A. ve Kane, E.J. (2000) "Effectiveness of Capital Regulation at US Commercial Banks, 19851994" The Journal of Finance, 55:451-469.

Jackson, P., Perraudin, W. ve Sapporta V. (2002) "Regulatory and Economic Solvency Standardsfor Internationally Active Banks" Journal of Banking ve Finance, 26:953-976. 
Jacques, K. ve Nigro, P. (1997) "Risk-Based Capital, Portfolio Risk, and Bank Capital: ASimultaneous Equations Approach" Journal of Economicsand Business, 49:533-547.

Jorgenson, A. K. (2009) "Political-Economic Integration, Industrial Pollution and Human Health: A Panel Study of Less-Developed Countries 1980-2000" International Sociology, 24(1):115-143.

Kahane, Y. (1977) "Capital Adequacyand the Regulation of Financial Intermediaries" Journal of Bankingand Finance, 1:207-218.

Kim, A. ve Jennings, E.T. (2009) "Effects of U.S. States' Social Welfare Systems on Population Health" The Policy Studies Journal, 37(4):745-767.

Kleff, V. ve Weber, M. (2003) "How Do Banks Determine Capital? Empirical Evidence From Germany" ZEW Discussion Paper, No:0366.

Koehn M ve Santomero M.A (1980) "Regulation of Bank Capital and Portfolio Risk" The Journal of Finance, 35(5):1235-1243.

Lin P. (2002) "Cost Efficiency Analysis of Commercial Bank Mergers in Taiwan" International Journal of Management, 19(3): 408-417.

Madura, J. ve Zarruk, E.R. (1993) "Market Reaction to Uniform Capital Aduquacy Guidelines in the Banking Industry" Journal of Economicsand Finance, 17(1):59-73.

Mathuva, D.M. (2009) "Capital Adequacy, Cost Income RatioandthePerformance of CommericalBanks: TheKenyanScenario" The International Journal of Applied Economics and Finance,3:35-47.

Modigliani, F. ve Miller, H.M. (1958) "The Cost of Capital, Corporation Finance and The Theory of Investment" American Economic Review, 48(3):261-297.
Mpuga, P. (2002) “The 1998-99 BankingCrisis In Uganda: What Was The Role of The New Capital Requirements?" Journal of Financial Regulationand Compliance, 10(3):224-242.

Rochet, J.C.(1992) "Capital Requirementsand the Behaviour of Commercial Banks" European Economic Review, 36:1137-1178.

Rudra, N. (2005) "Are Workers in Developing World Winners or Losers in the Current Era of Globalization?" Studies in Comperative International Development, 40(3):29-64.

Sorensen, B.E., Wu, L. ve Yosha, O. (2001) “Output Fluctuations and Fiscal Policy: U.S. State and Local Governments 1978-1994" European Economic Review, 45(7):1271-1310.

Tanaka, M. (2002) "How Do Bank Capital and Capital Adequacy Regulation Affect the Monetary Transmission Mechanism?" Cesifo Working Paper, No:799.

Wong, J., Choi, K., ve Fong, T. (2005) "Determinants of the capital level of banks in Hong Kong" Hong Kong Monetary Authority Quarterly Bulletin, September 2005: 14-37.

Wooldridge, J.M. (2000) Introductory Econometrics: A Modern Approach, Ohio, South Western College Publucation.

York, R. (2007) "Structural Influences on Energy Production in South and East Asia 1971-2002" Sociological Forum, 22(4):532-554. 